\title{
Alterations in Proinsulin and Insulin Dynamics, HDL Cholesterol and ALT After Gastric Bypass Surgery. A 42-Months Follow-up Study
}

\author{
Hans-Erik Johansson • Arvo Haenni • \\ Margareta Öhrvall • Magnus Sundbom • \\ Björn Zethelius
}

Published online: 27 May 2009

(C) Springer Science + Business Media, LLC 2009

\section{Erratum to: OBES SURG \\ DOI 10.1007/s11695-009-9806-x}

The surnames of the authors were incorrectly captured in the original publication. The correct authorship is as follows:

Hans-Erik Johansson, Arvo Haenni, Margareta Öhrvall, Magnus Sundbom, and Björn Zethelius. The abbreviated names in the footnote should read: H.-E. Johansson, A. Haenni, M. Öhrvall, M. Sundbom, and B. Zethelius.

\footnotetext{
The online version of the original article can be found at http://dx.doi. org/10.1007/s11695-009-9806-x

H.-E. Johansson $(\varangle) \cdot$ A. Haenni $\cdot$ M. Öhrvall $\cdot$ B. Zethelius Department of Public Health and Caring Sciences/Geriatrics, Uppsala University Hospital,

Uppsala Science Park,

75185 Uppsala, Sweden

e-mail: hans-erik.johansson@pubcare.uu.se

M. Sundbom

Department of Surgical Sciences, Uppsala University Hospital,

Uppsala, Sweden 